\title{
Study of Prenatal Arsenic Exposure and Reproductive Health Outcome in Bangladesh
}

\author{
SELINAAKHTER BANU, MOLLY L. KILE, DAVID C. CHRISTIANI, QAZI QUMRUZZAMAN
}

\begin{abstract}
:
Objective : There is growing concern that exposure to arsenic during pregnancy can have adverse effects on the developing fetus. To investigate the effect of arsenic exposure on reproductive health outcomes this study was carried out.
\end{abstract}

\begin{abstract}
Materials and methods : This prospective birth cohort study was carried out by Harvard School of Public Health and Dhaka Community Medical College \& Hospital in 2004 through the Sirajdikhan and Birahimpur community clinics as a pilot project. The study included 421 pregnancies at the time of enrollment. Water samples were collected at the time of enrollment and within one month of delivery from the tubewell of each participant identified as their primary source of drinking water. These samples were analyzed by inductively coupled plasma mass spectrometry.
\end{abstract}

Results: Of 421 pregnancies, 38 women withdrew from the study or were lost to follow up (9.0\%), 30 resulted in spontaneous abortion or miscarriage (7.1\%), 32 were stillbirths (7.6\%) and 321 were live births (76.2\%). At the time of enrollment, the average drinking water arsenic exposure level was $31.6 \mu \mathrm{g} / \mathrm{L}$ (standard deviation, $83.7 \mu \mathrm{g} / \mathrm{L}$; range, $<1-880 \mu \mathrm{g} / \mathrm{L}$ ). The average drinking water level at one month post delivery was $26.1 \mu \mathrm{g} / \mathrm{L}$ (standard deviation, $68.2 \mu \mathrm{g} / \mathrm{L}$, range: $<1$ to $460 \mu \mathrm{g} / \mathrm{L}$ ) which indicated that exposure to arsenic contaminated drinking water decreased during pregnancy. However, 31.9\% of all participants exceeded the World Health Organization's recommended drinking water arsenic level of $10 \mu \mathrm{g} / \mathrm{L}$ and $16.9 \%$ exceeded the Bangladesh drinking water arsenic regulation of $50 \mu \mathrm{g} / \mathrm{L}$. Sixty-three (40.9\%) of all women reported an illness during this pregnancy. The odds of reporting any illness during the current pregnancy was $51 \%$ higher for those women who used a tubewell that contained more than the Bangladesh drinking water standard during their pregnancy compared to pregnant women who used a tubewell that contained less than $50 \mu \mathrm{g} \mathrm{As} / \mathrm{L}$ adjusting for maternal age, maternal education, and pregnancy history (odds ratio, 1.51; 95\% confidence interval, 0.28, 8.16). Of the 321 live births, 64 (15.2\%) had a birthweight less than 2500 grams and were classified as low birthweight. The odds of a low birthweight infant was $32.3 \%$ greater for those women who used a tubewell that contained more than the Bangladesh drinking water standard during their pregnancy compared to pregnant women who used a tubewell that contained less than $50 \mu \mathrm{g} \mathrm{As} / \mathrm{L}$ adjusting for maternal age, maternal education, gestational age, infant sex, spouses education, mother's weight gain during the first 28 weeks, chewing betel nuts, reporting any illness during pregnancy, environmental tobacco smoke, and pregnancy history (odds ratio, 1.32; 95\% confidence interval, 0.19, 9.17). In this sample, 35 infants were born at less than 37 weeks gestational age (8.3\%) and were classified as preterm infants. The odds of a preterm infant was $84 \%$ greater for those women who used a tubewell that contained more than the Bangladesh drinking water standard during their pregnancy compared to pregnant women who used a tubewell that contained less than 50 $\mu \mathrm{g} A \mathrm{~s} / \mathrm{L}$ adjusting for maternal age, maternal education, spouses education, mother's weight gain during the first 28 weeks, environmental tobacco smoke, and pregnancy history (odds ratio, 1.84; 95\% confidence interval, 0.81, 4.17).

Conclusion: Arsenic exposure during pregnancy contributed to adverse maternal - child health outcomes. It is important to note that none of these associations reached statistical significant and it will be important to confirm these associations in the complete dataset.

Keyword : Prenatal, Arsenic, Drinking water, Reproductive outcome.

1. Associate Professor (C.C) Dept. of Gynae, Bangladesh Community Medical College Hospital

2. Assistant Professor, College of Public Health and Human Sciences, Oregon State University

3. Professor of Environmental Genetics, Harvard School of Public Health

4. Chairman, Dhaka Community Hospital Trust 


\section{Introduction:}

Arsenic is a metalloid that is widely distributed in the environment and people are exposed mainly through well water and to a lesser extent, through the food chain. Among the dietary source arsenic can be found mainly in seafood, rice cereals and poultry. Arsenic in food is present in the organic form, basically as methylated metabolites that are easily eliminated from body and widely assumed to be less toxic ${ }^{1}$. The inorganic form of arsenic present in drinking water is considered the most toxic form and classified as a human carcinogen by the International Agency for Research on cancer².

Worldwide millions of people are currently drinking groundwater that contains inorganic arsenic in concentrations exceeding the World Health Organization guideline value of $10 \mu \mathrm{g} / \mathrm{L}^{3}$. In some regions of Bangladesh, China, Chile and United States of America drinking water is the major source of human exposure due to the fact that ground water contains arsenic at concentrations in excess of $50 \mu \mathrm{g} / \mathrm{L}$. South Asia is particularly affected by naturally occurring arsenic in well water and exposures to concentrations above $100 \mu \mathrm{g} / \mathrm{L}$ are widespread in arsenic affected areas - West Bengal, India and neighboring Bangladesh constitute the most extensively contaminated regions in the World ${ }^{4,5}$.

It is estimated that $95 \%$ of the drinking water in Bangladesh is provided by tubewells, a type of well which involves driving a pipe or tube into the earth to tap into the aquifer as apposed to the more commonly known dug well. A survey of 10,377 tubewells in Bangladesh found that $73 \%$ of the sampled wells exceeded the World Health Organization's provisional arsenic drinking water limit of $10 \mu \mathrm{g} / \mathrm{L}$ and 59\% exceeded the Bangladesh drinking water standard of $50 \mu \mathrm{g} / \mathrm{L}$. These findings led the World Health Organization(WHO) to call this the largest mass poisoning of a population in history ${ }^{6}$.

Arsenic biomarkers include blood, urine, hair and nails. These tissues reflect the absorbed dose from all exposure routes. Of these biomarkers, blood is considered a relatively poor biomarker of exposure because absorbed arsenic is cleared rapidly from the blood stream. Urinary arsenic, on the other hand, is considered a good biomarker of recent exposure because it takes approximately 3 days to excrete 60$75 \%$ of the ingested dose. Also, the relative percentage of each urinary arsenic metabolite can be used to evaluate methylation ability, a potential factor for developing arsenic-induced disease. Unlike urine, hair and nails accumulate arsenic over time and sequester it from metabolic processes. Therefore, hair and nails can provide a cumulative exposure index which might be a better predictor of long-term exposure and risk of arsenic-induced diseases 7,8 .

Due to its ability to interrupt biochemical enzyme reactions, arsenic affects nearly all organ systems by binding to sulfhhydryl groups and replacing phosphorus in biochemical reactions. This can inhibit pyruvate and succinate oxidation, the Kreb's cycle, gluconeogenesis and reductive oxidative phosphorylation. Symptoms of chronic arsenic toxicity include hyperpigmentation of the skin that presents with a distinctive pattern of dark brown patches and scattered white spots; hyperkeratosis of the palms and soles; sensory and motor neuropathy that manifests as a numbness or tingling of the hands and feet; weakness of the limbs and inflammation of the respiratory tract. In addition, epidemiologic studies have found chronic ingestion of highly arsenic contaminated drinking water is significantly associated with dibetes mellitus, hypertension, peripheral and vascular disease and an increased risk of kidney, bladder, lung and skin cancer ${ }^{9-10}$.

Also a number of epidemiologic studies suggest that arsenic exposure via drinking water may affect early human development, but findings are mixed. Several studies have reported an association of arsenic exposure with spontaneous abortion and stillbirth, with about 2 to 3 times higher risks among women with high arsenic concentrations in their drinking water $(>50 \mu \mathrm{g} / \mathrm{L})^{11-14}$. Recently, one study from Bangladesh suggested that increases in spontaneous abortion, stillbirth \& neonatal death rates were associated with levels of arsenic in drinking water greater than $50 \mu \mathrm{g} / \mathrm{L}^{15}$.

There is emerging evidence that early-life exposures affect fetal and infant growth, mainly by epigenetic effects. The developing foetus particularly vulnerable to toxic insults, because of rapid cell division and differentiation, especially in the nervous system. Subsequently an increased awareness of the potential chronic health effects of arsenic at low exposure levels has motivated efforts to better understand morbidity and mortality, as well as impaired child development during pregnancy by using objective biomarkers of exposure ${ }^{16}$. 
Therefore, the aims of this study were to evaluate the prenatal exposure to arsenic, examine the effects on neonatal outcomes and investigate the association with maternal lifestyle and dietary habits during pregnancy.

\section{Materials and methods:}

This prospective birth cohort pilot study was carried out by Harvard School of Public Health and Dhaka Community Medical College \& Hospital in 2004 through the Sirajdikhan and Birahimpur Community Clinics. A total of 421 pregnant women agreed to participate in the study at the time of enrollment and informed consent was obtained from patient herself, her husband or any dependable relatives. A questionnaire was designed encompassing basic, socio-demographic, food habits, drinking water supply, sun exposure and all relevant clinical informations.

All pregnant women were eligible if they were 18 years or older, having a singletone pregnancy, less than 16 weeks of gestational age, use groundwater for drinking water source, regular antenatal check-up with a Dhaka Community Hospital (DCH) Clinic and delivered at home with a DCH trained midwife or at Dhaka Community Medical College Hospital if need caesarean section.

All patients were visited 4 times - within 16 weeks, at 28 weeks, during delivery and within 1 month of delivery.

Table-I

(Method of data collection)

\begin{tabular}{|c|c|c|c|}
\hline $\begin{array}{l}\text { Within } 16 \\
\text { weeks } \\
\text { (clinic) } \\
\text { visit 1 }\end{array}$ & $\begin{array}{l}28 \text { weeks } \\
\text { GA } \\
\text { (clinic) } \\
\text { visit } 2\end{array}$ & $\begin{array}{l}\text { Delivery } \\
\text { (Home/ } \\
\text { Hosp) } \\
\text { visit } 3\end{array}$ & $\begin{array}{l}<1 \text { month } \\
\text { (Home) } \\
\text { visit } 4\end{array}$ \\
\hline - Questionnaire & - Questionnaire & - Cord blood & • Questionnaire \\
\hline $\begin{array}{l}\text { - Blood } \\
\text { - Urine } \\
\text { - Hair } \\
\text { - Nail } \\
\text { - USG } \\
\text { - Water }\end{array}$ & $\begin{array}{l}\text { - Blood } \\
\text { - Urine } \\
\text { - USG }\end{array}$ & $\begin{array}{l}\text { - Placenta } \\
\text { - Birth record }\end{array}$ & $\begin{array}{l}\text { - Blood - Mat. } \\
\text { - Hair-Mat. Infant } \\
\text { - Nails-Mat. Infant } \\
\text { - Water }\end{array}$ \\
\hline
\end{tabular}

Table -1 showed, for visits $1,2 \& 4$ all pregnant women completed a behavioral and socio - demographic questionnaire. An ultrasonography was done along with collection of blood and urine sample in visit $1 \& 2$. A blood sample was also collected for genotyping. Participants were provided with sterile urine collection container and instructed to collect a first void urine sample in visit $1 \& 2$. The samples were frozen at $-20^{\circ} \mathrm{C}$. Frozen urine samples were thawed at room temperature, dispersed by ultrasonic wave and filtered through a SepPak C18 column to remove protein. An aliquot of 200 mls was used to determine arsenic species.

Hair sample was taken from nape of the neck and toenail clippings were collected from all ten toes from mother in visit 1 and both from mother \& infant in visit 4 and pooled to ensure sufficient mass for analysis. External contamination was removed from nails by sonicating samples in a $1 \%$ Triton X-100 solution for 20 minutes. Toenails were then rinsed repeatedly, dried, weighed and digested in nitric acid at room temperature. The resultant solution was diluted to $8 \%$ HNO3 and analyzed using an inductively-coupled plasma mass spectrometer.

At $3^{\text {rd }}$. visit during delivery either home or hospital, cord blood sample and placenta's tissue were collected and a birth record form was filled up. In last visit within 1 month of delivery at home a questionnaire was filled up, a blood sample was collected from the mother and samples of hair and nail were collected from both the mother and baby.

Water samples were collected at the time of enrollment and within one month of delivery from the tubewell of each participant identified as their primary source of drinking water. These samples were analyzed by inductively coupled plasma mass spectrometry.

\section{Results:}

General and reproductive characteristics of the study population are summarized in Table II.

\section{Table-II}

Demographic and reproductive baseline characteristics of participants $(n=421)$

\begin{tabular}{lcc}
\hline Characteristic & No. & Percentage \\
\hline Age in years at time of interview : & & \\
Median & 30 & \\
Range & $20-40$ & \\
Age in years at marriage : & & \\
$\leq 16$ & 256 & 61 \\
$>16$ & 165 & 39 \\
Participant's education : & & \\
No formal education - & 183 & 43 \\
Primary school - & 158 & 36 \\
Secondary school or higher - & 90 & 21 \\
Education of the husband : & & \\
No formal education - & 80 & 19 \\
Primary school - & 240 & 57 \\
Secondary school or higher & 101 & 24 \\
Number of pregnancies per women $:$ & \\
1-2 & 98 & 23 \\
$3-4$ & 186 & 44 \\
$\geq 5$ & 137 & 33 \\
\hline \hline
\end{tabular}


Of 421 pregnancies, 38 women withdrew from the study or were lost to follow up (9.0\%), 30 resulted in spontaneous abortion or miscarriage (7.1\%), 32 were stillbirths (7.6\%) and 321 were live births (76.2\%)( Table III ).

Table-III

Progress Report

\begin{tabular}{lcc}
\hline Parameters & $\begin{array}{c}\text { Number of } \\
\text { patients }\end{array}$ & $\begin{array}{c}\text { Percentage } \\
(\%)\end{array}$ \\
\hline Total recruited & 421 & $(100)$ \\
Withdrew from the study & 38 & $(9.0)$ \\
Spontaneous abortion or & 30 & $(7.1)$ \\
Miscarries & & \\
Stillbirths & 32 & $(7.6)$ \\
Live births & 321 & $(76.2)$ \\
\hline
\end{tabular}

Table - IV showed the results of distribution of arsenic concentration detected in participants drinking water. At the time of enrollment, the average drinking water arsenic exposure level was $31.6 \mu \mathrm{g} / \mathrm{L}$ (standard deviation, $83.7 \mu \mathrm{g} / \mathrm{L}$; range, $<1-880 \mu \mathrm{g} / \mathrm{L})$. The average drinking water level at one month post delivery was $26.1 \mu \mathrm{g} / \mathrm{L}$ (standard deviation, $68.2 \mu \mathrm{g} / \mathrm{L}$, range: $<1$ to $460 \mu \mathrm{g} / \mathrm{L})$ which indicated that exposure to arsenic contaminated drinking water decreased during pregnancy. However, $31.9 \%$ of all participants exceeded the World Health Organization's recommended drinking water arsenic level of $10 \mu \mathrm{g} / \mathrm{L}$ and $16.9 \%$ exceeded the Bangladesh drinking water arsenic regulation of $50 \mu \mathrm{g} / \mathrm{L}$.

\section{Table-IV}

The distribution of arsenic concentration detected in participants drinking water $(N=321)$

\begin{tabular}{lcccc}
\hline & Percentile & Average & SD & Range \\
\hline $\begin{array}{l}\text { Drinking water arsenic } \\
\text { at enrollment }(\mu \mathrm{gm} / \mathrm{L})\end{array}$ & - & 36.1 & $83.7<1-880$ \\
$\begin{array}{l}\text { Drinking water arsenic } \\
\text { at } 1 \mathrm{month} \text { postdelivery } \\
(\mu \mathrm{gm} / \mathrm{L})\end{array}$ & - & 26.1 & $68.2<1-460$ \\
$\begin{array}{l}\text { Exceed WHO } \\
\text { standered }(10 \mu \mathrm{gm} / \mathrm{L})\end{array}$ & $31.9 \%$ & - & - & - \\
$\begin{array}{l}\text { Exceed Bangladesh } \\
\text { standard }(50 \mu \mathrm{gm} / \mathrm{L})\end{array}$ & $16.9 \%$ & - & - & - \\
\hline
\end{tabular}

Table $V$ showed that sixty-three (40.9\%) of all women reported an illness during this pregnancy. Of the 321 live births, 35 (8.3\%) infants were born at less than 37 weeks gestational age and were classified as preterm infants, 64 (15.2\%) had a birthweight less than 2500 grams and were classified as low birth weight.
The odds of reporting any illness during the current pregnancy was $51 \%$ higher for those women who used a tubewell that contained more than the Bangladesh drinking water standard during their pregnancy compared to pregnant women who used a tubewell that contained less than $50 \mu \mathrm{g}$ As/L adjusting for maternal age, maternal education, and pregnancy history (odds ratio, 1.51; 95\% confidence interval, $0.28,8.16)$. The odds of a preterm infant was $84 \%$ greater for those women who used a tubewell that contained more than the Bangladesh drinking water standard during their pregnancy compared to pregnant women who used a tubewell that contained less than $50 \mu \mathrm{g} \mathrm{As/L}$ adjusting for maternal age, maternal education, spouses education, mother's weight gain during the first 28 weeks and pregnancy history (odds ratio, 1.84; $95 \%$ confidence interval, $0.81,4.17$ ). The odds of a low birthweight infant was $32.3 \%$ greater for those women who used a tubewell that contained more than the Bangladesh drinking water standard during their pregnancy compared to pregnant women who used a tubewell that contained less than $50 \mu \mathrm{g} \mathrm{As} / \mathrm{L}$ adjusting for maternal age, maternal education, gestational age, infant sex, spouses education, mother's weight gain during the first 28 weeks, chewing betel nuts, reporting any illness during pregnancy, environmental tobacco smoke, and pregnancy history (odds ratio, 1.32; 95\% confidence interval, 0.19, 9.17).

\section{Table-V}

Compairing the odds of each outcome for women who used tubewells with arsenic above and below Bangladesh standard

\begin{tabular}{lcccc}
\hline Parameters & $\begin{array}{c}\text { Total } \\
\text { patient }\end{array}$ & Percentile & $\begin{array}{c}\text { Odds } \\
\text { ratio }\end{array}$ & $95 \% \mathrm{Cl}$ \\
\hline $\begin{array}{l}\text { Reported an illness } \\
\text { during pg. }{ }^{1}\end{array}$ & 63 & $40.9 \%$ & 1.51 & $0.28,8.16$ \\
$\begin{array}{l}\text { Preterm (37 weeks })^{2} \\
\text { Low birth weight }\end{array}$ & 64 & $8.3 \%$ & 1.84 & $0.81,4.17$ \\
$(2500 \mathrm{gm} .)^{3}$ & $15.2 \%$ & 1.32 & $0.19,9.17$ \\
\hline
\end{tabular}

1 adjusted for maternal age, maternal education, and pregnancy history

2 adjusting for maternal age, maternal education, spouses education, mother's weight gain during the first 28 weeks, environmental tobacco smoke, and pregnancy history

3 adjusting for maternal age, maternal education, gestational age, infant sex, spouses education, mother's weight gain during the first 28 weeks, chewing betal nuts, reporting any illness during pregnancy, environmental tobacco smoke, and pregnancy history 


\section{Discussion:}

The biologic effect mechanism by which arsenic may affect the developing fetus is still unclear, and whether differences in arsenic methylation during pegnancy may be related to particular susceptibility of the fetus to arsenic is unknown. Recent studies reported that arsenic crosses the human placenta, although more than $90 \%$ of the arsenic in plasma and urine was in the form of dimethylarsinic acid, indicating an increase in the methylation of arsenic during pregnancy. Maternal toxicity has also been found to be associated with the adverse developmental effects of arsenic exposure. Maternal toxicity may in some instances be the causative factor in abnormal development of the embryos. This is probably the result of induction of metallothionein in the maternal liver that leads to a systemic redistribution of zinc and a transitory but developmentally adverse, zinc deficiency ${ }^{13,17}$.

Arsenic levels in blood, urine, hair and nails have all been investigated and used as biological indicators of exposure to arsenic. In human blood typical values in non exposed individuals are in the range of 0.5 to $2 \mu \mathrm{gm} / \mathrm{L}$. However, the urine is generally accepted as the most reliable indicator of recent arsenic exposure. The normal level for an unexposed person is usually less than $50 \mu \mathrm{gm} / \mathrm{L}^{18}$. Furthermore, arsenic tends to accumulate in hair and nails, and measurement of arsenic levels in these tissues may be a useful indicator of past exposure. Normal levels in hair and nails are $1 \mu \mathrm{gm} / \mathrm{L}$ or less. Recently, prenatal exposure to arsenic was estimated by testing it in placenta ${ }^{19}$. As an assumption, we can use levels detected in placenta, as a fetal tissue that may be a useful indicator of prenatal exposure.

Increased risk of spontaneous abortion, stillbirth, preterm birth and neonatal death at elevated water arsenic concentrations were indicated by some authors, when mothers were interviewed about previous pregnancies. Moreover, other authors point out a moderately increased risk of impaired foetal growth and increased fetal \& infant mortality with prenatal exposure to arsenic ${ }^{11,13,14,20}$. There are also few studies indicating that infants born to women who drink water with elevated arsenic concentrations during pregnancy have a lower birth weight ${ }^{21}$.

In this study the risk of adverse pregnancy outcomes at several concentrations of arsenic in drinking water was assessed. The findings suggest an association between chronic arsenic exposure through drinking water and spontaneous abortion and stillbirth. Rates of reported spontaneous abortion and stillbirth were somewhat higher in this study (71 per 1,000 livebirths and 76 per 1,000 livebirths, respectively) than in the
Indian National Family Health Survey (40 per 1,000 livebirths and 18 per 1,000 livebirths, respectively) ${ }^{21}$. In this study, spontaneous abortion was $7.1 \%$, stillbirths was $7.6 \%$ which were differ from Ehrenstein et al study who found no association with arsenic concentration for spontaneous abortion, while a six fold increase risk for stillbirth ${ }^{14}$. In this study low-birth weight was in 15.2\% (OR 1.32, 95\% Confidence Interval $0.19,9.17)$ which was not comparable to Huyck et al studies where, birth-weight was higher than non exposed individuals ${ }^{22}$. So far none of these studies have individually assessed arsenic concentrations in all water sources used during each pregnancy in relation to spontaneous abortion, stillbirth, and infant mortality.

There was no good documentation of pregnancy outcomes available in the study area, so we had to rely on the respondents when obtaining information. Hence, there is a chance of recall bias through differential recall of adverse pregnancy outcomes among those with higher exposure to arsenic if the respondent's well was colorcoded correctly. Interviewer bias is less likely because the interviewers were unaware of the arsenic concentration levels of the subject's usual drinking water source. Furthermore, we had information for only 1 well for each woman, and so her cumulative duration of arsenic exposure could not include exposure from other wells. The amount of drinking water consumed was also not considered in this study.

There could be variation in adverse pregnancy outcomes that is related to the amount of the exposed water the woman drank on average. Nevertheless, the strength of this study is the availability of individual arsenic exposure data and determination of risk at different arsenic concentration levels. Our data support the accumulating evidence that chronic arsenic exposure is associated with an increased risk of spontaneous abortion and stillbirth. Larger case-control studies are needed to confirm associations between arsenic and adverse pregnancy outcomes.

\section{Conclusion:}

The determination of toxic elements in the biological samples of human beings is an important clinical screening procedure. In this study arsenic exposure during pregnancy contributed to adverse maternal child health outcomes. It is important to note that none of these associations reached statistical significant and this preliminary analysis need to be confirmed in the entire cohort. Therefore, further epidemiologic studies are required to confirm the results suggested and for understanding the mechanisms related with prenatal arsenic exposure. 


\section{References:}

1. Huq SM, Joardar JC, Parvin S, Correll R, Naidu R. Arsenic Contamination in food-chain : transfer of arsenic into food materials through groundwater irrigation. J Health Popul Nutr. 2006; 24 : 305-316.

2. International Agency for Research on Cancer (IARC). Working Group on the Evaluation of Carcinogenic Risks to Humans. Some DrinkingWater Disinfectants and Contaminants Including Arsenic. IARC Monogr Eval Carcing Risks Hum. 2004; 84 : 1-477.

3. World Health Organization. Guidelines for drinking water quality, Geneva, Switzerland : World Health Organization, 2004.

4. Chowdhury UK, Biswas BK, Choudhury TR, et al. Groundwater arsenic contamination in Bangladesh and West Bengal, India. Environ Health Perspect. 2000; 108: 393-397.

5. Chakraborti D, Mukherjee SC, Pati S, et al. Arsenic ground- water contamination in middle Ganga Plain, Bihar, India : a future danger? Environ Health Perspect 2003 ; 111 : 1194-1201.

6. Smith, A. H. , Lingas, E.O., and Rahman M. Contamination of drinking- water by arsenic in Bangladesh : a public health emergency. Bulletin of the World Health Organization, 2000; 78 : 1093-1103.

7. Calderon R., Hudgens E., Le X., Schreinemachers D., and Thomas D. Excretion Of Arsenic in Urine as a function of Exposure to Arsenic in Drinking Water. Environmental Health Perspectives. 1999; 107: 663-667.

8. Karagas M. R, Tosteson T. D, Blum J, Klaue B, Weiss J. E, et al. Measurement of Low Levels of Arsenic Exposure: A Comparison of Water and Toenail Concentrations. Americal Journal of Epidemiology, 2000; 152 : 84-90.

9. Chowdhury U.K., Rahman M.M., Mondal B.K., Paul K. et al. Groundwater Arsenic Concentration and Human Suffering in West Bengal, India and Bangladesh. Environmental Science. 2001; 8: 393-415.

10. Milton $\mathrm{AH}, \mathrm{Rahman} \mathrm{M}$. Environmental pollution and skin involvement pattern of chronic arsenicosis in Bangladesh. J Occup Health. 1999: 41 : 207-208.
11. Ahmed SA, Sayed MH, Barua S et al. Arsenic in drinking water and pregnancy outcomes. Environ Health Perspect. 2001; 109: 629-631.

12. Vahter M. Effects of arsenic on maternal and fetal health. Annu Rev Nutr. 2009; 29 : 381-399.

13. Milton AH, Smith WP, Rahman B, et al. Chronic arsenic exposure and adverse pregnancy outcomes in Bangladesh. Epidemiology. 2005; 16: 82-86.

14. Von Ehrenstein OS, Guha Mazumder DN, Hira - Smith M, et al. Pregnancy outcomes, infant mortility and arsenic in drinking water in West Bengal, India. Am J Epidemiol. 2006; 163: 662-669.

15. Rahman A, Vahter M, Ekstrom EC, et al. Association of arsenic exposure during pregnancy with fetal loss and infant death: a cohort study in Bangladesh. Am J Epidemiol. 2007, 165: 1389-1396.

16. Rahman A, Vahter $M$, Smith $A H$, Nermell $B$, Yunus $M$, et al. Arsenic exposure during pregnancy and size at birth : a prospective cohort study in Bangladesh. Am J Epidemiol. 2009; 169: 304-312.

17. Concha G, Vogler G, Legeano D, et al. Exposure to inorganic arsenic metabolites during early human development. Toxicol Sci. 1998; 44: 185-190.

18. National Research Council. Arsenic in Drinking Water. Update. Washington, DC : National Academy Press: 2001.

19. Vall O, Culebras G.M, Algar OG, Joya X, Velez $D$, et al. Assessment of Prenatal Exposure to Arsenic in Tenerife Island. PLoS One 2012; 7(11) EL: e50463.

20. Rahman A, Persson LA, Nermell B, Arifeen S, Ekstrom EC, et al. Arsenic exposure and risk of spontaneous abortion, stillbirth and infant mortality. Epidemiology. 2001; 21 : 799-804.

21. International Institute for population Sciences and Macro International, Inc. National Family Health Survey (NFHS-2) - West Bengal, Mumbai, India and Washington DC, 2001.

22. Huyck KL, Kile ML, Mahiuddin G, Zaman Q, Rahman $\mathrm{M}$ et al. Maternal arsenic exposure associated with low birth weight in Bangladesh. J Occup Environ Med. 2007; 49: 1097-1104. 